\title{
The effect of humic acids adsorption on pH-dependent surface charging and aggregation of $\mathrm{Fe}_{3} \mathrm{O}_{4}$-APTES nanoparticles
}

Bondarenko L. ${ }^{1}$, Illes I. ${ }^{2}$, Tombácz E. ${ }^{2}$, Magomedov I. ${ }^{1}$, Rabinskiy L. ${ }^{1}$, Kydralieva K. ${ }^{1}$

${ }^{1}$ Moscow Aviation Institute, Moscow, Russia, I.s.bondarenko92@gmail.com

${ }^{2}$ University of Szeged, Szeged, Hungary

Keywords: magnetite, 3-aminopropyl-triethoxysilane, humic acids, isoelectric point, zeta-potential

doi: 10.36291/HIT.2019.bondarenko.104

Humic acids ( $\mathrm{HA})$ are often used as a stabilizer for magnetite nanoparticles $\left(\mathrm{Fe}_{3} \mathrm{O}_{4}\right)$ and as a functional component for magnetic nanocomposites. Despite the protective shell of $\mathrm{HA}$ the oxidative degradation of $\mathrm{Fe}_{3} \mathrm{O}_{4}$ to maghemite $\mathrm{Fe}_{2} \mathrm{O}_{3}$ nanoparticles is observed. This led to a change in the biological activity of the composite (Terekhova et al., 2018). To improve chemical stability of $\mathrm{Fe}_{3} \mathrm{O}_{4}$ the surface charge control was used through pretreatment using silanes. In this study, effect of $\mathrm{HA}$ adsorption on $\mathrm{pH}$-dependent surface charging and aggregation of the $\mathrm{Fe}_{3} \mathrm{O}_{4}$ functionalized by 3-aminopropyl-triethoxysilane (APTES) was studied. A set of the $\mathrm{Fe}_{3} \mathrm{O}_{4}$-APTES samples were formulated: under argon (Ar) or air atmosphere and/or further dialysis (D) and subsequent treatment of the samples: in harsh (US-treatment) and mild (magnetic stirrer, $M$ ) conditions. As a total, five samples were obtained: $\mathrm{Fe}_{3} \mathrm{O}_{4}, \mathrm{Fe}_{3} \mathrm{O}_{4}$-APTES (Ar), $\mathrm{Fe}_{3} \mathrm{O}_{4}$-APTES (Ar-D-M), $\mathrm{Fe}_{3} \mathrm{O}_{4}$ APTES (Ar-D-US), and $\mathrm{Fe}_{3} \mathrm{O}_{4}$-APTES (air).

Magnitude of isoelectric points (iep, the $\mathrm{pH}$ of $\xi=0$ ), zeta-potential and hydrodynamic size were measured at $25 \pm 0.1{ }^{\circ} \mathrm{C}$ in a disposable zeta cell (DTS 1060) of NanoZS (Malvern, UK) apparatus [2]. The range of $\mathrm{pH}$ was between $\sim 3$ and $\sim 10$. According to the magnitude of the shift of the $\mathrm{pH}$-dependent zeta potential functions due to the sorption of increasing amount of $\mathrm{HA}$ in case of all samples, it is possible to formulate a series of samples in which the sorption capacity decreases: $\mathrm{Fe}_{3} \mathrm{O}_{4}$-APTES (Ar-D-M) $\geq$ $\mathrm{Fe}_{3} \mathrm{O}_{4}$-APTES(air) $>\mathrm{Fe}_{3} \mathrm{O}_{4} \geq \mathrm{Fe}_{3} \mathrm{O}_{4}$-APTES(Ar-D-US) $>>\mathrm{Fe}_{3} \mathrm{O}_{4}$-APTES (Ar).

Treatment way has a great effect on the sorption capacity of the samples. Dialysis of the sample $\mathrm{Fe}_{3} \mathrm{O}_{4}$-APTES (Ar) led to enhance adsorbing of $\mathrm{HA}$. The sample exposed to the magnetic stirrer has a larger sorption capacity than the sample after the US-treatment: $\mathrm{Fe}_{3} \mathrm{O}_{4}$-APTES (Ar-D-M) $>\mathrm{Fe}_{3} \mathrm{O}_{4}$-APTES (Ar-D-US) $>>\mathrm{Fe}_{3} \mathrm{O}_{4}$-APTES (Ar). It is likely that harsh conditions during sonication (extreme high temperature and pressure in cavities forming at interfaces) led to destroy $\mathrm{Fe}_{3} \mathrm{O}_{4}$-APTES-HA bonds and reduce the sorption capacity.

The hydrodynamic diameter increases near the isoelectric point for the samples $\mathrm{Fe}_{3} \mathrm{O}_{4}$-APTES without $\mathrm{HA}$. The hydrodynamic size for the samples $\mathrm{Fe}_{3} \mathrm{O}_{4}$-APTES at $\mathrm{pH}<$ 5 and $\mathrm{pH}>9$ varied from $700 \mathrm{~nm}$ to $300 \mathrm{~nm}$. In the range $5<\mathrm{pH}<9$, the hydrodynamic size is about 100-300 $\mathrm{nm}$. But, the hydrodynamic diameter for $\mathrm{Fe}_{3} \mathrm{O}_{4}$-APTES the increases near the isoelectric point (from 200 to $750 \mathrm{~nm}$ ), when not fully coverage with HA. In case of full coverage with $\mathrm{HA}$, the hydrodynamic size remains unchanged at all $\mathrm{pH}$ range (around $150 \mathrm{~nm}$ for all of samples).

Acknowledgements. This research has been financed by the Russian Foundation for Basic Research (\#19-33-90149I19) and the IHSS (Training Award, the University of Szeged).

\section{References}

1. Terekhova V. et al. // In: The 19th International Conference of International Humic Substances Society, 16-21 September 2018, Bulgaria. P. 205.

2. Tombácz E. et al. // Colloids and Surfaces A: Physicochemical and Engineering Aspects. 2013. 435:91-96. 